\title{
Dissemination and Utilization of Physics Education Research Findings: Towards Enhanced Teaching and Learning of Physics in Secondary School
}

\author{
Bello Theodora Olufunke (Ph.D) \\ Institute of Education, Obafemi Awolowo University, Ile-Ife, Nigeria \\ EMail: bledore@oauife.edu.ng
}

\author{
Akinfesola Omowumi Esther \\ Department of Science and Technology Education, Obafemi Awolowo University, Ile-Ife, Nigeria
}

\author{
Doi:10.5901/mjss.2015.v6n6s4p333
}

\begin{abstract}
The study ascertained the different ways by which Physics education research findings are disseminated to Physics teachers. It also determined the factors affecting the dissemination and utilization of Physics education research findings to senior secondary schools and investigated Physics teachers' attitude to the dissemination and utilization of research findings. These were with a view to understanding the usefulness of Physics education research findings to secondary school teachers. The study used descriptive survey research design. The population comprised Physics teachers of senior secondary schools in southwestern Nigeria. The sample comprised 120 senior secondary school Physics teachers selected using multi stage sampling technique from 60 schools in three states in the southwestern Nigeria. The instruments used for data collection were Physics Education Research Findings Dissemination Questionnaire (PERFDQ) and Questionnaire on Factors Affecting Dissemination and Utilization of Physics Research Findings (QFDUPRF). Data collected were analyzed using frequency counts and percentages. The results showed that Physics education research findings (PERF) were disseminated to Physics teachers through the internet, libraries, textbooks, seminars / workshops, colleagues, journals, research studies from universities, documentaries and Ministry of Education. The results also showed that factors affecting the dissemination and utilization of PERF were that larger number of the teachers could not get adequate fund to purchase different textbooks that provide information on research findings; many of the teachers did not appreciate Physics research findings on newspaper; the government was unable to provide adequate research funding to be used by the teachers. The results further showed that very high percentage of the teachers showed a positive attitude towards PERF dissemination and utilization. The study concluded that majority of Physics teachers in senior secondary schools utilized the Physics education research findings disseminated to them, and this has helped to improving their students' academic performance.
\end{abstract}

Keywords: Dissemination, Utilization, Attitude, Research Findings, Academic Performance.

\section{Introduction}

Science is important in the technological growth and the economic sustenance of any nation. Science and technology are key drivers to any nation development, because technological and scientific revolutions underpin economic advances, improvements in health systems, education and infrastructure (Lee-Roy, 2012). Technology as an instrument for accelerating development should receive special attention in national planning in the developing countries. Government should make policies that favour the uptake of science products and those that help to transform science into technology for the benefit of mankind. Also government efforts must be addressed to establish an industry-university cooperation to communicate technological advances to potential users (Bilsel and Oral, 1995).

Physics was found to be the bedrock of scientific and technological development worldwide in both developed and developing countries. Physics as one of the branches of science is an important subject that must be well known and passed before any science student could further in the line of science in any tertiary institution. Physics deals with energy and matter and their interactions. It is sometimes referred to as the science of measurement and its knowledge has contributed greatly to the production of instruments and devices of tremendous benefits to the human race. The knowledge of Physics plays a very significant role in the development of any nation. The importance of Physics cannot be over emphasized as it forms the basis for technological advancement of any nation. Physics plays a vital role in the development of any society (Sani, 2012). The teaching of Physics in secondary schools is intended to produce young scientists who would be able to design the technological devices that would make day-to-day activities easier and living more comfortable (Ajayi, 2008). It thus implies that Physics is one of the pivotal subjects in technology. The teaching and 
learning outcomes of this subject need serious attention in order to enhance a sustainable technological development in Nigeria.

Despite the importance of Physics to the scientific and technological development of any nation, yet students' performance in the subject is not encouraging. The performances of students in Senior Secondary School Certificate Examination (SSCE) over the years is presented in table 1

Table 1: Students' Achievement in the May/June Physics Examination between 2004 and 2013

\begin{tabular}{|l|c|c|c|c|c|}
\hline Year & Total Number of Candidates & Number of Credit Pass & \% Pass & Number of Fail & $\%$ Fail \\
\hline $\mathbf{2 0 0 4}$ & 265,262 & 135,359 & 51.03 & 129,903 & 48.97 \\
\hline $\mathbf{2 0 0 5}$ & 345,640 & 144,132 & 41.70 & 201,508 & 58.30 \\
\hline $\mathbf{2 0 0 6}$ & 379,823 & 221,450 & 58.30 & 158,373 & 54.89 \\
\hline $\mathbf{2 0 0 7}$ & 419,245 & 181,092 & 43.19 & 238,153 & 56.81 \\
\hline $\mathbf{2 0 0 8}$ & 405,913 & 195,922 & 48.26 & 209,991 & 51.74 \\
\hline $\mathbf{2 0 0 9}$ & 454,802 & 146,341 & 32.18 & 308,461 & 67.82 \\
\hline $\mathbf{2 0 1 0}$ & 487,963 & 159,264 & 32.64 & 328,699 & 67.36 \\
\hline $\mathbf{2 0 1 1}$ & 563,161 & 360,096 & 63.94 & 203,065 & 36.06 \\
\hline $\mathbf{2 0 1 2}$ & 624,658 & 429,415 & 68.74 & 195,243 & 31.26 \\
\hline $\mathbf{2 0 1 3}$ & 636,857 & 296,910 & 46.62 & 339,947 & 53.38 \\
\hline
\end{tabular}

Source: West African Examination Council, Research and Statistics Unit 2015

The table above indicated a consistent decline in students' performance over the past 10 years. In the year 2004 and 2010, over $50 \%$ of the students failed the Physics examination. But over $50 \%$ of the students passed the examination in the year 2011 and 2012 and another failure of over 50\% in 2013. This revealed that all the research efforts towards the teaching and learning of Physics to improve students' performance have not made much difference. The low performance of students in school certificate examination has deprived many of them the opportunity to pursue science and technology-oriented careers in higher institutions. It is therefore imperative to proffer ways of minimizing low performance of students in Physics so that they can have more opportunities to pursue career in science and technology.

\section{Literature Review}

Many authors have carried out research on factors that are responsible for poor performance of students in science and especially in Physics. Inappropriate teaching methods used by Physics teachers had resulted in this low performance of students (Owolabi and Oginni, 2013). Sunday (2010) stated that the inability of making use of a variety of non-verbal teaching aids for a number of reasons by the teachers tends to contribute to the low level of instruction of Physics in schools. Changeiywo (2000) as cited in Bello (2012) revealed that students who had negative ideas towards scientists, science and technology in society are easily discouraged from achieving scientific disciplines and often performed poorly in science subjects.

It was ascertained that improving the learning of Physics and achievement through the use of appropriate teaching equipment and teaching methods are important to the successful teaching and learning of Physics (Bello, 2012). Similarly, Jegede and Adedayo (2013) suggested that Physics teachers should use appropriate teaching methods that are relevant to their students. They said no method is the best, but the teachers need to study their students and identify the best teaching method for them. Sunday (2010) recommended that the method of teaching Physics should be guided-discovery method instead of the old and routine lecture method used in teaching the subject. Hindrances to students learning must be identified and addressed in a way that leads to more effective learning (David 2002). Teacher needs to encourage the students by making Physics interesting and captivating to them. Their relationship with the students everywhere should not scare them away but rather draw their interest towards the study of Physics (Jegede and Adedayo, 2013).

Despite the fact that there had been series of research in this area, not much improvement has been recorded in the teaching and learning of the subject. This raises doubts as to the usage of Physics education research findings in the areas of teaching methods and students' motivation. Literature is devoid of uptake of research outputs by Physics teachers to enhance their teaching methodology, thereby improving on the teaching and learning of Physics. This study therefore aims at assessing the dissemination and utilization of Physics education research findings by Physics teachers in senior secondary schools of southwestern Nigeria. 


\subsection{Purpose of the Study}

The main goal of this study is to assess the dissemination and utilization of Physics education research findings by Physics teachers in Nigerian secondary schools. Therefore, the specific objectives are to:

(i) ascertain the different ways by which Physics education research findings are disseminated to Physics teachers;

(ii) determine the factors affecting the dissemination and utilization of Physics education research findings to senior secondary schools; and

(iii) investigate Physics teachers' attitude to the dissemination and utilization of research findings in Physics education.

\subsection{Research Questions}

The following research questions were raised to guide the study

(i) What are the different ways by which Physics education research findings are disseminated to Physics teachers in senior secondary schools?

(ii) What are the factors affecting the dissemination as well as utilization of Physics education research findings in the schools?

(iii) What is the attitude of Physics teachers to the dissemination and utilization of research findings in Physics education?

\subsection{Significance of the Study}

The effect of research findings in Physics could hardly be felt on the performance of the secondary school students offering the subject. Therefore, the result of the study is expected to assist the Physics teachers get vital information on the relevance of Physics education research findings to the teaching and learning of Physics. It would provide an insight on the processes involved in disseminating Physics education research findings to Physics teachers. It would also give useful information on factors hindering the utilization of Physics education research findings by teachers.

The Ministry of Education has an important role to play in making sure that Physics education research outcomes are utilized by teachers or to those who formulate education policy, this study would therefore provide empirical information that would guide them on how they would monitor and evaluate the conduct of research; organize and support the dissemination of research findings through seminars, workshops and publications.

\section{Methodology}

\subsection{Research Design}

This study used descriptive survey research design. Since the population is relatively large, there is need to select a representative portion from where necessary data were collected for the study. This is provided for by survey research design. This is a research technique in which data are gathered by asking questions from respondents. It describes in a systematic manner, the characteristics, features or facts about a given population.

\subsection{Sample}

The sample consisted of 120 senior secondary school Physics teachers. Multi-stage sampling technique was used to select the sample. Three states were sampled from the six southwestern states using simple random selection technique. Two Local Government Areas (LGAs) were selected from each state in the region using simple random sampling technique to make a total of six LGAs. Ten senior secondary schools were then selected from each LGA also using simple random sampling technique to make a total of 60 schools. Physics teachers in the schools were selected using purposive sampling techniques. It is purposive because only the senior Physics teachers were selected.

\subsection{Research Instruments}

Two research instruments were used for data collection. These were two sets of questionnaires which were developed by the researcher to collect data from Physics teachers. The first questionnaire was titled "Physics Education Research Findings Dissemination Questionnaire" (PERFDQ). It contained two sections. Section A consisted of items, which deal 
with their personal data while section B comprised items on ways by which research findings are disseminated to Physics teachers. The second questionnaire was titled "Questionnaire on Factors Affecting Dissemination and Utilization of Physics Research Findings" (QFDUPRF). It contained two sections. Section A comprised items that sought for information on the factors affecting the dissemination and utilization of Physics education research findings while section B sought for information on teachers' attitude to the dissemination and utilization of research findings. In the first instrument, teachers were expected to indicate their views by filling in the provided gaps (open-ended) and ticking their choice of answer (close-ended question). In the second instrument, teachers were expected to pick their choice of answer in section $A$, and in section $B$ which is a Likert-type rating scale rated on 4 points with Strongly Agree (SA=4), Agree $(A=3)$, Disagree $(D=2)$ and Strongly Disagree $(S D=1)$. The face validity of the instrument was established by the researcher and experts in the field of education. Their corrections were followed in selecting the items included in the instruments. Pilot testing was carried out by administering the instruments on 25 teachers from co-educational secondary schools different from the selected schools used for the study. Cronbach alpha method was used to determine the reliability of the research instruments. The results of the reliability coefficients were 0.68 and 0.77 which were obtained for PERFDQ and QFDUPRF respectively.

\subsection{Procedure for Data Collection}

The researcher visited the schools selected for the research with copies of Physics Education Research Findings Dissemination Questionnaire (PERFDQ) and Questionnaire on Factors Affecting Dissemination and Utilization of Physics Research Findings (QFDUPRF) and these were administered on the Physics teachers in the selected senior secondary schools in Southwestern Nigeria. Permission was taken from the school principals before the researcher was allowed to administer questionnaires on the teachers. The respondents filled the questionnaires while the researcher waited to collect some of the questionnaires the day they were administered on the teachers. The remaining copies of the questionnaires were collected later by the researcher. All the copies of the questionnaires distributed were collected from the respondents. The data collected were analyzed using frequency counts, and percentages for the parameters used in the study.

\section{Results}

Results of the analysis are presented according to research questions.

Research Question One: What are the different ways by which Physics education research findings are disseminated to Physics teachers in senior secondary schools?

In answering this question, teachers were required to respond to items based on different ways research findings can be disseminated. The summary of their responses are given in table 2

Table 2: Ways through which Research Findings are Disseminated to Physics Teachers

\begin{tabular}{|c|l|c|c|c|}
\hline S/N & Research Findings Dissemination Media & Yes (\%) & No (\%) & None \\
\hline 1 & Seminars/ workshops & $104(86.7)$ & $12(10.0)$ & $4(3.3)$ \\
\hline 2 & Conferences & $84(70.0)$ & $36(30)$ & - \\
\hline 3 & Educational journals/ periodicals & $104(86.6)$ & $16(13.3)$ & - \\
\hline 4 & Newspapers & $56(46.6)$ & $64(53.3)$ & - \\
\hline 5 & Textbooks & $108(90.0)$ & $12(10)$ & - \\
\hline 6 & Ministry of Education & $84(70.0)$ & $33(27.5)$ & $3(2.5)$ \\
\hline 7 & Internet & $116(96.6)$ & $4(3.3)$ & - \\
\hline 8 & News on television & $64(53.3)$ & $56(46.6)$ & - \\
\hline 9 & News on radio & $32(26.6)$ & $88(73.3)$ & - \\
\hline 10 & Documentary & $88(73.3)$ & $32(26.6)$ & - \\
\hline 11 & Research studies in the universities & $96(80.0)$ & $24(20)$ & - \\
\hline 12 & In-service training programme & $100(83.3)$ & $20(16.6)$ & - \\
\hline 13 & Libraries & $112(93.3)$ & $8(6.6)$ & - \\
\hline 14 & Colleagues & $104(86.7)$ & $12(10.0)$ & $4(3.3)$ \\
\hline
\end{tabular}

The results in table 2 indicated that teachers had access to Physics education research findings through Internet (96.6\%), Libraries (93.3\%), Textbooks (90.0\%), Seminars/ workshops (86.7\%), Educational journals/ periodicals (86.7\%), 
Colleagues (86.7\%). Others are In-service training programme (83.3\%), Research studies in universities (80.0\%), Documentary (73.3\%), Conferences and Ministry of Education (70.0\%). The result further showed that News on television (53.3\%), Newspapers (46.6\%) and News on radio (26.6\%) are the least ways by which Physics education research findings are disseminated to Physics teachers.

Research Question Two: What are the factors affecting the dissemination as well as utilization of Physics education research findings in senior secondary schools?

Teachers' responses to the statements that sought for information on the factors that cause the dissemination and utilization of Physics education research findings were collected and analyzed. The results of the analysis were presented on table 3.

Table 3: Factors Affecting the Dissemination and Utilization of Physics Research Findings by Teachers

\begin{tabular}{|c|l|c|c|c|}
\hline S/N & Statement & Yes (\%) & No (\%) & None \\
\hline 1 & Do you search for research findings on internet? & $112(93.4)$ & $4(3.3)$ & $4(3.3)$ \\
\hline 2 & Do you have time to attend in-service training programme? & $88(73.3)$ & $26(21.6)$ & $6(5.0)$ \\
\hline 3 & Do you have access to research findings on documentaries? & $80(66.7)$ & $36(30.0)$ & $4(3.3)$ \\
\hline 4 & Do you have interest in the reading of journals/periodicals? & $104(86.7)$ & $11(9.2)$ & $5(4.2)$ \\
\hline 5 & Are research findings on newspaper appreciated by you? & $40(33.3)$ & $80(66.7)$ & - \\
\hline 6 & Do schools sponsor the attendance at seminars/ workshops that discuss research findings? & $64(53.3)$ & $40(33.3)$ & $16(13.3)$ \\
\hline 7 & $\begin{array}{l}\text { Do you have adequate fund to purchase different textbooks that provide information on } \\
\text { research findings? }\end{array}$ & $36(30.0)$ & $80(66.7)$ & $4(3.3)$ \\
\hline \multirow{2}{*}{8} & $\begin{array}{l}\text { Do the School administrators allow you to attend conferences which discuss research } \\
\text { findings? }\end{array}$ & $92(76.7)$ & $28(23.3)$ & \\
\hline 9 & Are the research findings gotten from television useful to Physics teaching? & $72(60.0)$ & $40(33.3)$ & $8(6.7)$ \\
\hline 10 & Do you apply research developments gotten from seminars/ workshops during teaching? & $112(93.3)$ & $5(4.2)$ & $3(2.5)$ \\
\hline 11 & Are students ready to adapt to the new teaching methods used? & $116(96.7)$ & - & $4(3.3)$ \\
\hline 12 & Are schools resistant to change in using new teaching methods? & $32(26.7)$ & $80(66.7)$ & $8(6.7)$ \\
\hline 13 & Does the government provide adequate research developments to be used? & $8(6.7)$ & $100(83.3)$ & $12(10.0)$ \\
\hline 14 & Are you able to utilize the research findings from documentaries? & $84(70.0)$ & $29(24.2)$ & $7(5.8)$ \\
\hline 15 & Do you use research studies from the universities? & $76(63.3)$ & $35(29.2)$ & $9(7.5)$ \\
\hline 16 & Do your teaching techniques get improved as you utilized the Physics research findings? & $116(96.7)$ & - & $4(3.3)$ \\
\hline
\end{tabular}

The results in table 3 showed that $93.4 \%$ of the teachers have time to search for research findings on internet; $73.3 \%$ of them had time to attend in-service training programme; $66.7 \%$ of them had access to research findings on documentaries and use them; $86.7 \%$ of the teachers had interest in the reading of journals/periodicals with majority of them (66.6\%) not appreciating research findings in newspaper. Furthermore, $53.3 \%$ of the teachers were sponsored by their schools to attend seminars/ workshops. Majority of them $(66.7 \%)$ do not have fund to purchase different textbooks that provide information on research findings. The school administrators allowed good percentage of them (76.6\%) to attend conferences that discussed research findings. Also, $60.0 \%$ of the teachers ascertained that research findings got from television were useful to Physics. The research developments gotten from seminars/ workshop were applied during teaching by $93.3 \%$ of the teachers, with $96.7 \%$ of them opined that students were ready to adapt to new teaching methods. Although, some schools (26.7\%) were resistant to change in using new teaching methods but majority of them $(66.7 \%)$ were ready to use another method of teaching. Most of the Physics teachers (83.3\%) opined that government did not provide adequate research development for schools. In addition, $63.3 \%$ of the Physics teachers utilized the research studies from universities, with $96.7 \%$ of them having their teaching techniques improved as they utilized Physics research findings. findings?

Research Question Three: What is the attitude of Physics teachers to the dissemination and utilization of research

In giving answers to this question, teachers gave responses to items concerning their attitude to the dissemination and utilization of research findings. The summary of the mean of their responses and standard deviation are given in table 4. 
Table 4: Summary of Means and Standard Deviation for the Items measuring Physics Teachers' Attitude to the Dissemination and Utilization of Research Findings

\begin{tabular}{|lcccc|}
\hline Variable & N & Mean & SD \\
\hline Physics Teachers' Attitude to the Dissemination and Utilization of Physics Research Findings & 120 & 3.27 & 0.2312 \\
\hline
\end{tabular}

The result in table 4 shows the overall mean and standard deviation of 3.27 and 0.2312 respectively. The mean value is measured against a minimum possible score of 2.5. It can be deduced from the mean score that the Physics teachers' attitude to the dissemination and utilization of Physics research findings is positive, this is an indication that most of them would be ready to use Physics research outputs if they have access to them.

\section{Discussion}

The findings of the study revealed that Physics teachers have different ways research findings were disseminated to them. Dissemination and utilization of the research findings were also affected by some factors. Also there were different attitudes showed by teachers towards the dissemination and utilization of these research findings. The results from research question one showed that Physics teachers got to know about Physics education research findings through seminars/ workshops, conferences. This was supported by Community Alliance for Research and Engagement (2001) that attending seminars and conferences were common methods for informing people about research findings. Also, they got research information majorly through the reading of educational journals / periodicals, newspapers and textbooks. Furthermore, they have access to Physics education research findings through Ministry of Education, internet, news on television and radio, watching of documentaries. Research findings were also gotten from universities, in-service training programme, libraries and colleagues etc.

Also, results from research question two which aimed at finding the factors affecting the dissemination and utilization of Physics education research findings to senior secondary schools. revealed that majority of the teachers did not appreciate Physics research findings on newspaper. Larger number of the teachers could not get adequate fund to purchase different textbooks / materials that provide information on research findings. This was in agreement with Njoku (2000) who stated that those that are aware of the use of materials in teaching are hindered by lack of funds. Majority of the teachers were of the opinion that government did not provide adequate research development for the schools. According to Jegede and Adedayo (2013) and Bello (2012), government needs to provide adequate relevant functioning materials and equipment for Physics laboratory.

Furthermore, results for research question showed that high percentage of the teachers found workshop I seminars that involved research findings interesting. Many of them never see the innovation of teachings methods as a stress and a large number of them enjoyed conferences where research findings are taught. Also, reading of journals was not boring to many of them while a large number of them like watching research developments on documentaries, and majority of them believed that attending in-service training programme was the best way teaching and learning of Physics could be improved. Largest percentage of teachers enjoyed using research findings, and this had improved their teaching techniques. A very high percentage of the teachers perceived the utilization of research findings as a must, and they did not see the utilization of research findings as burdensome to them.

The uptake of research findings for the development of teaching and learning is very essential, and it is important that people who are experts at promoting research uptake are engaged. According to Lomas (1997) and Weiss (1977), dissemination of research findings is a strategy that requires specific training of certain individuals who are competent and knowledgeable about promoting the uptake of research findings. They should also be highly skilled at communicating research findings to decision makers (Charlotte, 2001). Furthermore, currently, it is nobody's job to disseminate research evidence, or to ensure that needs of the policy makers' are brought into the research process before the commencement of research (Lomas; 1997 Weiss, 1977 and Desbarats, 1994). This calls for urgent attention to be given to research dissemination and uptake especially in Physics education.

\section{Conclusion}

Based on the outcome of this assessment study, it was concluded that Physics teachers in senior secondary schools have access to Physics education research findings. These findings were disseminated to them through meetings such as seminars, workshops, and conferences. Teachers also have access to research findings through the Ministry of Education, libraries, colleagues, internet, news on television and radio, reading of journals/ periodicals, documentaries etc. 
From the findings, it was also concluded that many of the teachers were ready to attend meetings where research findings could be disseminated to them. In contrast, government had not been helpful in the provision of adequate research findings for teachers. Majority of the teachers did not search for research findings on newspapers and larger percentage could not afford adequate fund to purchase different textbooks that would provide information on research findings.

Furthermore, it was concluded that majority of the teachers showed a positive attitude towards PERF dissemination and utilization as they found research findings disseminated at workshop/ seminars/ conferences interesting, and enjoy the reading of journals/ periodicals. Many of the teachers made use of disseminated research findings each time they were gotten.

The findings of the study have been able to provide vital information on the relevance of Physics education research findings to the teaching and learning of Physics. It has provided an insight on the processes involved in disseminating Physics Education research findings to Physics teachers. It has also given useful information on factors hindering the utilization of Physics education research findings by teachers.

\section{Recommendations}

On the basis of the findings of this study and conclusion reached, the following recommendations were made;

1. Government in collaboration with the Ministry of Education should intensify their effort at educating Physics teachers in senior secondary schools in attending conferences, workshops and seminars so that they can have access to current information (PERF) that will enhance the teaching and learning of Physics.

2. Government should also provide adequate facilities that will encourage research development for the teaching and learning of Physics in senior secondary schools.

3. Government should intensify efforts to monitor the utilization of Physics education research findings disseminated to teachers at the in-service training programme, conferences, and workshops / seminars.

\section{References}

Ajayi, P. O. (2008). Evaluation of instructional materials for the implementation of senior secondary school Physics Curriculum in Nigeria. Nigeria Journal of Counseling and Applied Psychology. 4 (1). 100-110

Bello, T. O. (2012). Effect of Availability and Utilization of Physics Laboratory Equipment on Students' Academic Achievement in Senior Secondary School Physics. World Journal of Education, Vol. 2(5), 1-7

Bilsel, A., \& Oral, O. (1995). Role of education, science and technology in developing c ountries. In: Frontiers in education annual; Eastern Mediterranean University, Gazimagusa, North Cyprus Turkey, vol.2, pp 4c4.11-4c4.14

Changeiywo, J. M. (2000). Students' Image of Science in Kenya: A comparison by Gender difference of Schooling and Regional Disparities. Unpublished Ph. D. Thesis, Egerton University Kenya.

Charlotte, W. (2001). So much research evidence, so little dissemination and uptake: mixing the useful with the pleasing: Evidence Based Mental Health, 4:3-5 doi:10.1136/ebmh.4.1.3

Community Alliance for Research and Engagement (2001). Beyond Scientific Publication: Strategies for Disseminating Research Findings. A Strong New Haven is a Healthy New Haven.

David, E. M. (2002). The relationship between Mathematics preparation and conceptual learning gains in Physics: A possible "hidden variable" in diagnostic pretest scores. pp 1259-1268.

Desbarats, P. (1994). The media and the dissemination of research. In: Dunn E, Norton P, Stewart M, et al, editors. Disseminating research, changing practice. Thousand Oaks, CA: Sage Publications, 76-86.

Jegede, S. A., \& Adebayo, J. O., (2013). Enriching Physics education in Nigeria towards enhancing a sustainable technology development. Greener Journal of Educational Research, 3 (2), 80-84.

Lee-Roy, C. (2012). The Role of Science and Technology in the Developing World in the 21 $1^{\text {st }}$ Century. www.ieet.org/index.php/ IEET/more/chetty20121003

Lomas, J. (1997). Improving research dissemination and uptake in the health sector: beyond the sound of one hand clapping. Hamilton, Ontario: McMaster University Centre for Health Economics and Policy Analysis.

Njoku, Z. C. (2000). Training science, technology and Mathematics teachers for improvisation: Educators as facilitators. $41^{\text {st }}$ Annual Conferences proceedings of STAN. 42-44.

Owolabi, O. T. \& Oginni, O. I. (2013). Assessing the relative effectiveness of three teaching methods in the measurement of students' performance in Physics. International Journals of Material, Methods and Technologies, 1(8), 116-125

Sani, A. (2012). Role of Physics education for technological development for employment and self-productivity in Nigeria. Journal of Educational and Social Research, vol 2

Sunday, A. A. (2010). Teaching / Learning of Physics in Nigerian Secondary Schools: The Curriculum Transformation, Issues, Problems and Prospects. International Journal of Educational Research and Technology, vol. 1(1), 99-111.

Weiss, C. H., (1977). Using social research in public policy making. Lexington, MA: Lexington Books. 